\title{
Food Consumption among Peasant Agriculturist Societies In 8000 BC
}

\section{Rukam Singh Tomar', Ran Singh Tomar ${ }^{2}$ and RB Singh ${ }^{3,4 *}$}

${ }^{1}$ Department of Biotechnology, Junagarh Agriculture University, Gujarat, India

${ }^{2}$ Directorate of Ground Nut Research, ICAR, Junagarh, Gujrat, India

${ }^{3}$ National Academy of Agriculture Science, New Delhi, India

${ }^{4}$ Halberg Hospital and Research Institute, Moradabad, India

After settlement of hunter-gatherers as peasants, man started farming in Africa for the first time, sometime in 8000 BC. This may be an adaptation which in turn led to unprecedented technical development, agriculture, industry and commerce [1-4]. Obviously prior to the Agricultural revolution and notwithstanding the Neolithic Revolution, sometimes called the Agricultural Revolution concerned with the initial transition from hunter-gather to settled agriculture. Our diet had great diversity characterized with enormous variety of whole grains and wild plants as well as fish, milk, egg and meat by hunting [1-4]. Peasant Agriculturist man, like hunter-gatherers, also had excellent health characteristics; enormous physical activity with limited or no mental stress, alcoholism, and tobacco intake that are now important behavioral risk factors of non-communicable diseases (NCDs). The foods available to early peasants, were not unhealthy like today's modern foods which are high energy but have poor nutrient density [1-4] (Tables 1). In this editorial, we discuss the food diversity, nutrient content and functions of various foods and nutrients available during Agricultural revolution compared to foods available now and what can be done to develop functional foods security.

The settlement of hunter-gatherers as farmers may have been associated with regular farming and storing of foods resulting in to better economic status which is known to have adverse effects on food, nutrition and health [5]. These foods grown in the farms may be characterized with a decrease in the consumption of protective omega-3 fatty acids, vitamins, antioxidants and amino acids and significant increase in the intakes of carbohydrates rich grains, fat rich meat (saturated and linoleic acid) and salt compared to the foods available to early hunter-gatherers and Paleolithic society [1-4]. The protein or amino acid intake was 2.5 fold greater (33 vs. 13\%) in the Paleolithic diet of Homo sapiens compared to modern Western diet which should have started decreasing right from the period of peasant Agriculturists (Table 1) [1-6].

\section{Food Security}

FAO's latest estimates indicate that the proportion of the world's population suffering from under nourishment may be around 12.5 percent, down from almost half of the world's population in 1947 [7]. Today about $17 \%$ of plant species provide $90 \%$ of the world's food supply which is mainly contributed by grains produced by fertilizer based on rapidly grown crops which may result in a decrease in nutrient density and increase in energy. Wheat, corn and rice account for three fourths of the world's grain production on which humans are dependent for their food supply [6,7]. Grains are high in omega-6 fatty acids and carbohydrates and low in omega- 3 fatty acids and antioxidants compared to leafy green vegetables. Green leafy vegetables are also rich sources of antioxidants, magnesium, w-3 fatty acids and carotenoids which appear to be high in the Mediterranean region [1-6]. Methods of Agriculture and foods make fundamental contributions to human nutrition through production, prices and incomes, but agriculture and the broader food system including post-harvest processing, distribution and retailing, can contribute much more. Food systems as a whole, from production through consumption, can be made more nutrition-enhancing and more environmentally sustainable through a number of specific actions that are identified in the FAO report [7].

An estimated, 2 billion people suffer from one or more micronutrient deficiencies and an estimated 1.4 billion people are overweight, of whom 500 million people are obese. Efforts should be made to correlate basic data on diets and on nutritional status; conduct impact evaluation of agricultural food-based interventions on nutritional outcomes. Encouragement and management practices and technologies may be used to improve sustainability and nutrition. There is enormous evidence which has been documented about the protective effects of Paleolithic diets in the form of Mediterranean diet, Indo-Mediterranean diet, Japanese diet, and DASH diet in the prevention of diseases [4-6]. Therefore, it is food security of functional foods, rather than modern foods, which appear to be important consideration for evolving human health and for prevention of NCDs. Plant breeding and genetic modifications are latest technologies for developing diversity in foods by altering nutrient content of foods, to solve the problem of functional food security [8]. Green revolution had contributed greatly to staple plant food productivity but without consideration on micronutrient. These stable crops can be enriched with micronutrients using plant breeding strategies, because micronutrient enrichment traits exist within their genomes that can to use for substantially increasing micronutrient levels in these foods without any negative impact on crop productivity. It may be possible to increase protective nutrients; omega-3 fatty acids, monounsaturated fatty acids, flavonoids, amino acids, vitamins and antioxidants and soluble fiber and decrease harmful nutrient contents; saturated fat, linoleic acid, sugar and erucic acid in a food by these two methods. In future, attempt should be made urgently, to develop omega-3 fatty acid and flavonoid rich slowly absorbed foods for control of undernutrition so that there is no increase in obesity which is important for prevention of NCDs.

*Corresponding author: RB Singh, Halberg Hospital and Research Institute Civil Lines, Moradabad-10 (UP) 244001, India, Tel: +919512417437; E-mail: rbs@tsimtsoum.net, drkk@dataone.in

Received July 15, 2013; Accepted July 17, 2013; Published July 22, 2013

Citation: Tomar RS, Tomar RS, Singh RB (2013) Food Consumption among Peasant Agriculturist Societies In 8000 BC. J Socialomics 2: e119. doi:10.4172/2167-0358.1000e119

Copyright: ( 2013 Tomar RS, et al. This is an open-access article distributed under the terms of the Creative Commons Attribution License, which permits unrestricted use, distribution, and reproduction in any medium, provided the original author and source are credited. 
Citation: Tomar RS, Tomar RS, Singh RB (2013) Food Consumption among Peasant Agriculturist Societies In 8000 BC. J Socialomics 2: e119. doi:10.4172/2167-0358.1000e119

Page 2 of 3

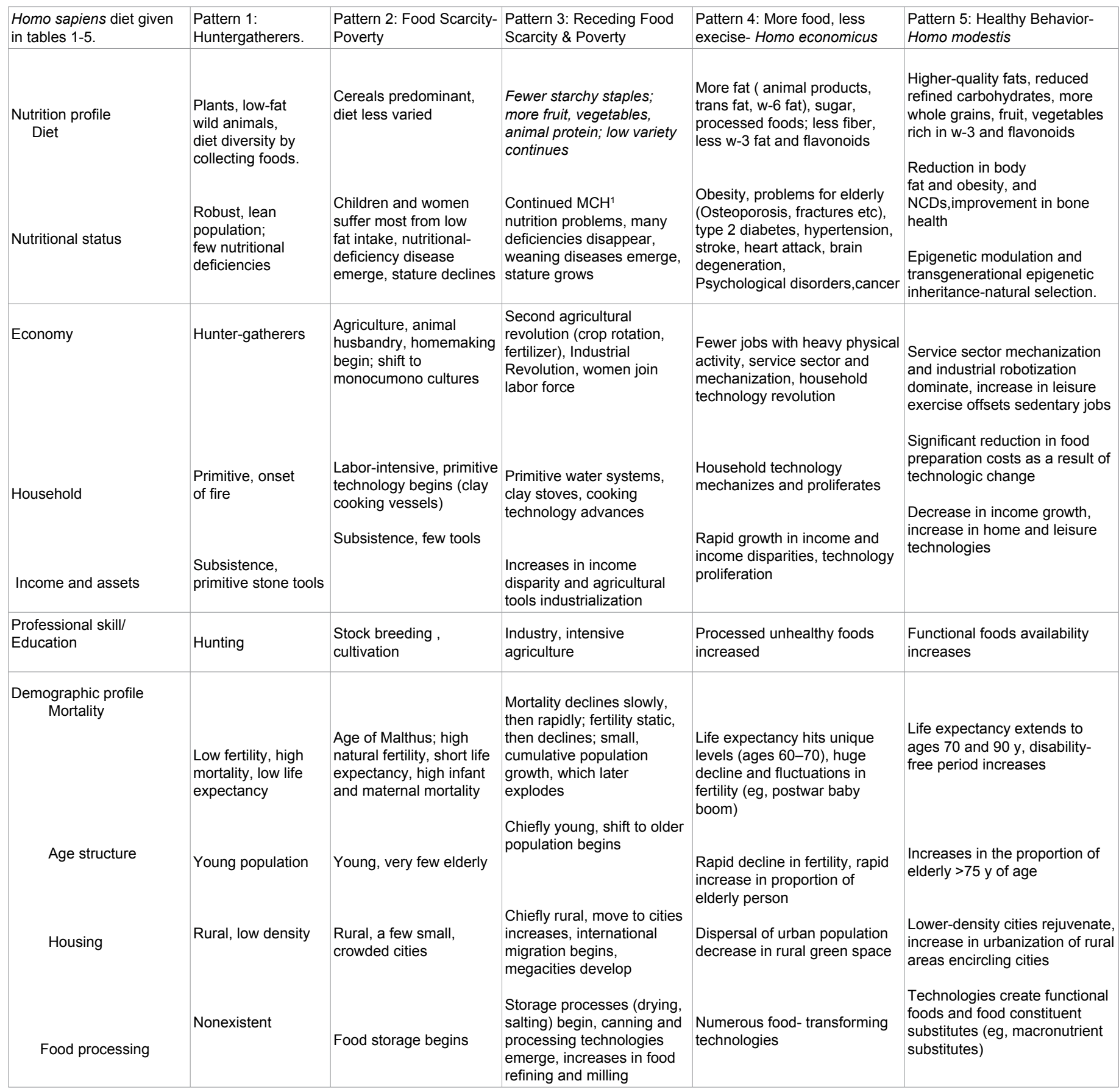

${ }^{1} \mathrm{MCH}$, maternal and child health, Modified from Singh et al. [4].

Table 1: Nutrition in transition and emergence of non-communicable diseases.

\section{Conflict of Interest}

No conflict of interest has been declared by the authors.

\section{Acknowledgement}

Acknowledgements are due to the International College of Nutrition and International College of Cardiology for providing logistic support to write this article.

\section{References}

1. Singh RB, Reddy KK, Fedacko J, De Meester F, Wilczynska A, et al. (2011) Ancient concepts in nutrition and diets in hunter-gatherers. The Open Nutra 4: 130-135.
2. Lindeberg S (2010) Food and Western Disease: Health and Nutrition from an Evolutionary Perspective. Chichester, UK: Wiley-Blackwell, pp. 368

3. Eaton SB, Konner M (1985) Paleolithic nutrition. A consideration of its nature and current implications. N Engl J Med 312: 283-289.

4. Singh RB, Takahashi T, Nakaoka T, Otsuka K, Toda E, et al. (2013) Nutrition in transition from Homo sapiens to Homo economicus. The Open Nutra J 6: 6-17.

5. Singh RB, Hristova K, Muthusamy VV, Rastogi SS, Basu TK, Toda E, et al (2013) The adverse effects of wealth on cardiovascular health: a scientific statement of the international college of cardiology. Cardiology and Angiology: an international journal 1: 9-22.

6. De Meester F (2008) Wild-type land based foods in health promotion and 
Citation: Tomar RS, Tomar RS, Singh RB (2013) Food Consumption among Peasant Agriculturist Societies In 8000 BC. J Socialomics 2: e119. doi:10.4172/2167-0358.1000e119

Page 3 of 3

disease prevention: the LDL-CC:HDL-CC model. In: Wild TypeFoods in Health Promotion and Disease Prevention, (Ed.) Fabien DeMeester, RR Watson, Humana Press, NJ, pp. 3-20

7. FAO, UNO The State of Food and Agriculture: Sustainable Food Systems for Food Security and Nutrition.
8. Welch RM, Graham RD (2004) Breeding for micronutrients in staple food crops from a human nutrition perspective. J Exp Bot 55: 353-364. 